\title{
4. POTENTIAL ORGANIC GEOCHEMICAL CONTAMINANTS ON BOARD THE JOIDES RESOLUTION
}

\author{
Keith W. Dunham ${ }^{1}$
}

\section{INTRODUCTION}

During Ocean Drilling Program Leg 103, potential sources of organic geochemical contamination were collected for shipboard analysis. These potential contaminants need to be distinguished from naturally occurring geochemical patterns for two reasons. First, the chief responsibility of the shipboard organic geochemist is to monitor for significant hydrocarbon accumulations that may pose safety concerns. Second, determination of potential contaminants is important for subsequent shore-based work. This analysis was proposed not to obtain detailed compositional information on potential contaminants but to provide quick "fingerprint" chromatograms useful in determining the presence of contaminants in the sample being examined.

\section{EXPERIMENTAL METHODS AND RESULTS}

To provide real-time analysis on board ship, analyses were of whole samples instead of fractionated aliphatic and aromatic hydrocarbons. Small sample amounts were dissolved in hexane before analysis. Chromatograms were obtained on a Hewlett Packard (HP) 5890 gas chromatograph, using splitless injection on a 20-m HP methyl silicone (0.20-mm inner diameter) fused silica capillary column. Running conditions were as follows: column flow, $1.0 \mathrm{~mL} / \mathrm{min}$ at $120^{\circ} \mathrm{C}$; temperature $1,75^{\circ} \mathrm{C}$; rate $1,15^{\circ} \mathrm{C} /$

\footnotetext{
${ }^{1}$ Oceanography Program, The University of Michigan, Ann Arbor, MI
}

min; temperature $2,120^{\circ} \mathrm{C}$; rate $2,6^{\circ} \mathrm{C} / \mathrm{min}$; temperature 3 , $270^{\circ} \mathrm{C}$; hold, $20 \mathrm{~min}$. Chromatograms were collected using the shipboard HP lab automation system (LAS) and plotted using the shipboard software plotting program CPLOT.

Figure 1 shows the individual chromatograms of the whole faction. For this shipboard study, identification of individual compounds was based on retention-time comparison with known standards.

\section{CONCLUSION AND RECOMMENDATIONS}

1. Owing to the vast amount of potential shipboard contaminants on board the JOIDES Resolution, extreme caution must be taken during drilling operations as well as during sampling procedures.

2. Unfortunately, no specific markers exist in most of the potential contaminants to aid in their quick identification. Therefore, it is important for the shipboard organic geochemist to become familiar with drilling procedures and identify potential contamination areas.

3. With the LAS on board, a library of shipboard contaminants should be extended, updated, and reviewed frequently by shipboard organic geochemists.

\section{ACKNOWLEDGMENTS}

I thank shipboard chemist Brad Julson for sample collection and laboratory assistance, ODP for making possible my participation on Leg 103, and Philip A. Meyers for suggesting this note. 

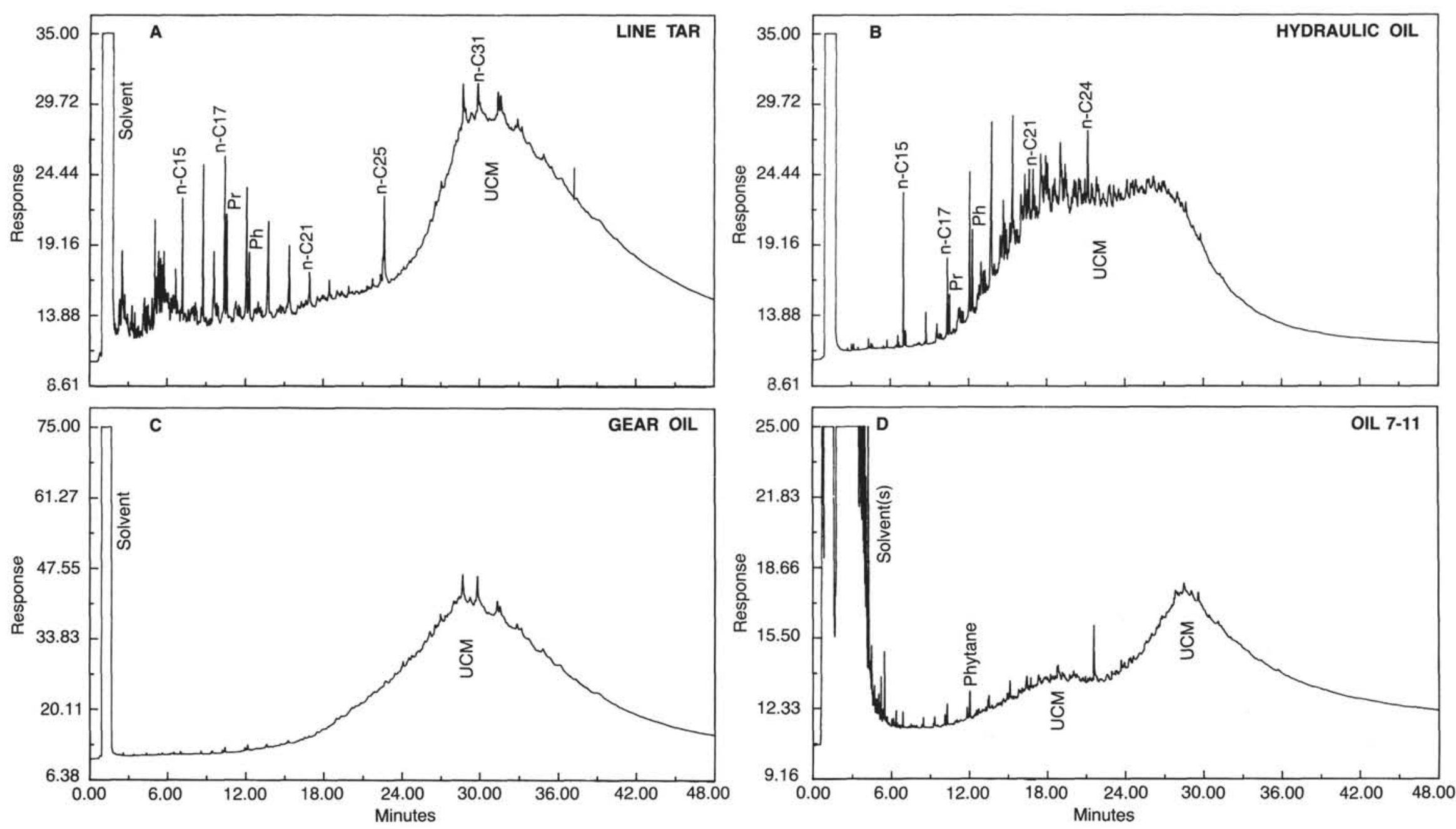

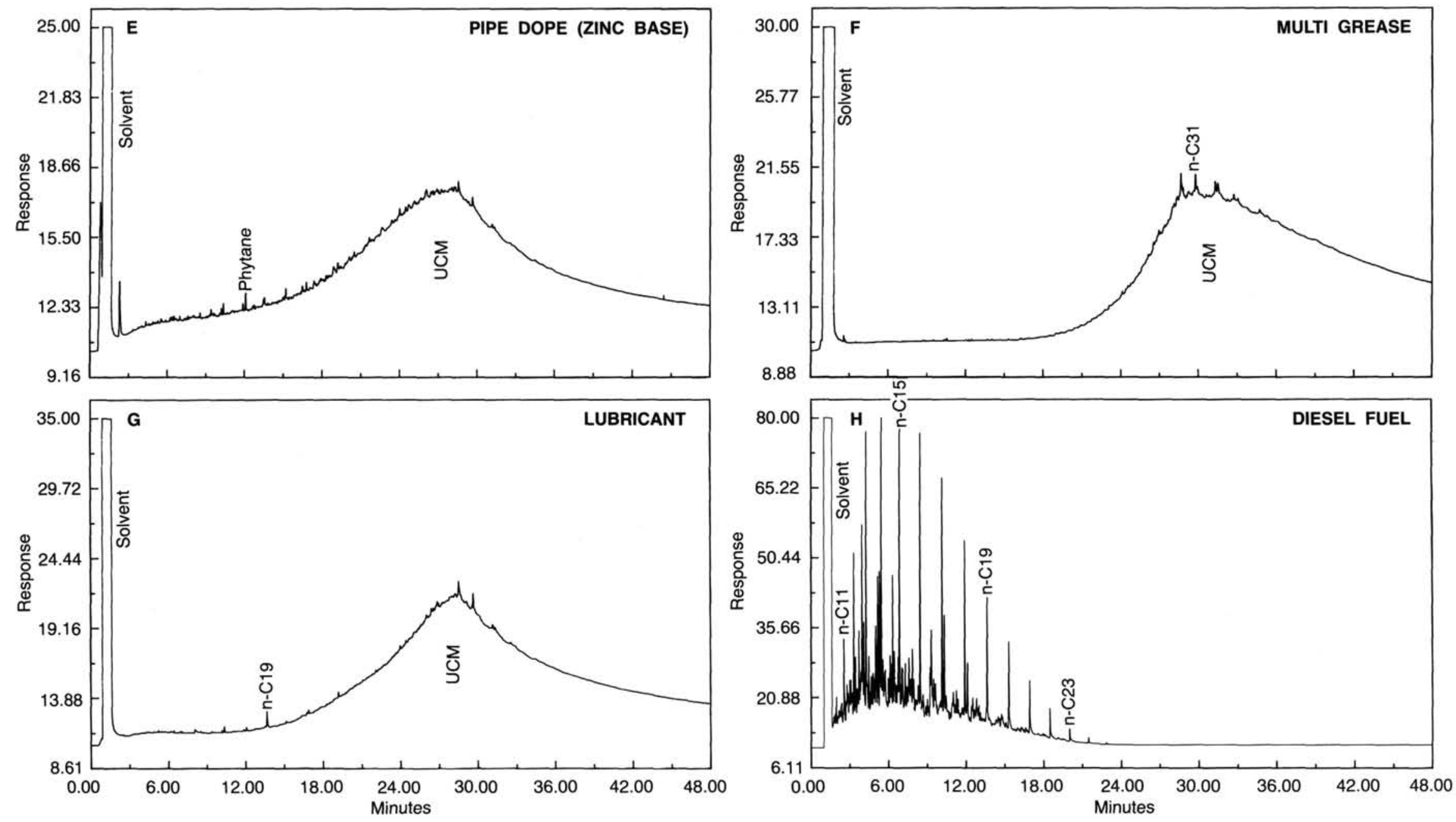

Figure 1. Gas chromatography trace of potential shipboard contaminants: (A) line tar, (B) hydraulic oil, (C) gear oil, (D) oil 7-11, (E) pipe dope (zinc base), (F) multi grease, (G) lubricant, (H) diesel fuel, (I) rock saw LP1, (J) pipe dope (lead base). 

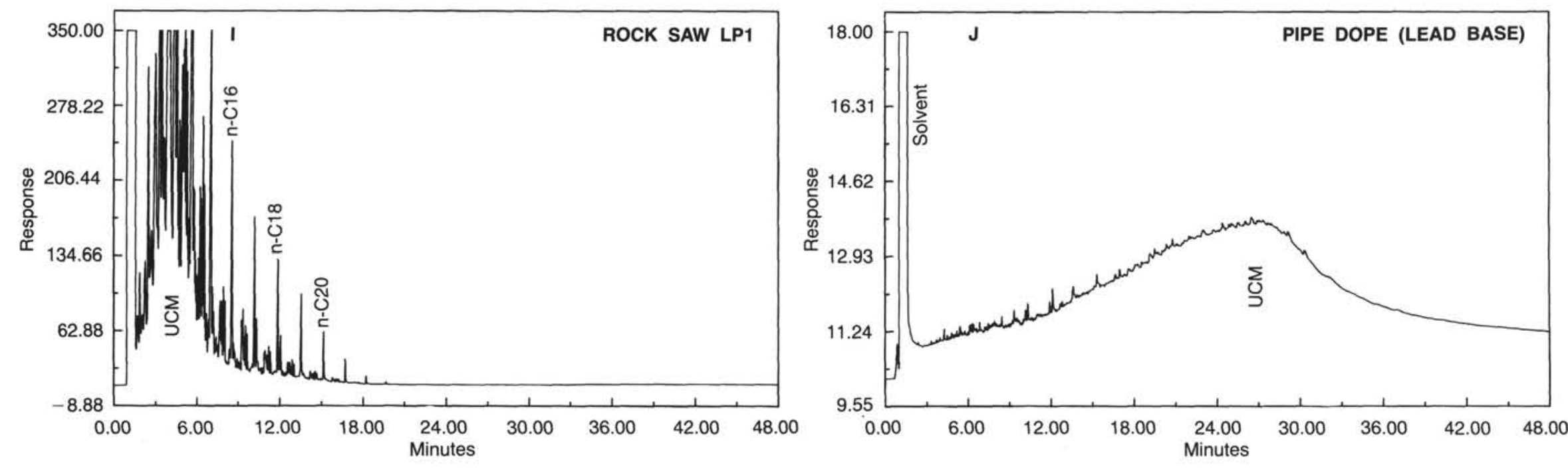

Figure 1 (continued). 